\title{
Prospection inventaire dans la Vallée de la Canche et ses affluents dans la région d'Étaples
}

\section{Françoise Bostyn}

\section{(QpenEdition Journals}

Édition électronique

URL : http://journals.openedition.org/adlfi/9857

ISSN : 2114-0502

Éditeur

Ministère de la culture

Référence électronique

Françoise Bostyn, «Prospection inventaire dans la Vallée de la Canche et ses affluents dans la région d'Étaples ", ADLFI. Archéologie de la France - Informations [En ligne], Nord-Pas-de-Calais, mis en ligne le 01 mars 1997, consulté le 20 avril 2019. URL : http://journals.openedition.org/adlfi/9857

Ce document a été généré automatiquement le 20 avril 2019

(C) Ministère de la Culture et de la Communication, CNRS 


\title{
Prospection inventaire dans la Vallée de la Canche et ses affluents dans la région d'Étaples
}

\author{
Françoise Bostyn
}

Date de l'opération : 1991 - 1992 (PI)

Inventeur(s) : Bostyn Françoise

1 La prospection inventaire dans la région d'Étaples s'est déroulée en trois phases complémentaires l'une de l'autre.

2 Dans un premier temps, un inventaire des gisements préhistoriques et historiques connus dans cette région a été réalisé. À partir des données de fouilles, des prospections aériennes et des ramassages de surface, des cartes d'implantation et d'occupation du sol aux différentes périodes ont été faites; elles mettent en évidence la densité et la continuité de la fréquentation de cette région naturellement favorable à une installation humaine depuis le Paléolithique moyen jusqu'à nos jours.

Une campagne de prospection au sol a permis de découvrir deux nouveaux gisements de surface, situés tous les deux dans la vallée de la Course, petit affluent de la Canche. Le premier est un site protohistorique (au sens large) caractérisé par la présence de matériel lithique en surface, non détruit par la charrue. Il s'agit de produits de débitage,de grattoirs, d'un percuteur et d'une feuille de gui. Le second site a livré de nombreux fragments de céramiques (fragments d'assiettes, de tèles, de céramiques vernissées vertes, d'éléments de préhension) qui permettent de présumer d'une occupation au Bas Moyen Âge dans ce secteur.

4 Des sondages à la pelle mécanique ont également été réalisés dans deux secteurs du projet d'aménagement de la zone industrielle «Opalopolis ", à1 km à l'est d'Étaples. Le premier est situé à proximité du gisement néolithique (Gallia Préhistoire, 33, p. 83-135) et gallo- 
romain des Sablins; la réalisation de sondages dans cette zone avait pour objectif d'en mesurer l'extension.

Il s'agissait de mesurer l'extension des deux occupations au-delà de la zone enclose et fouillée partiellement. Les tranchées ont permis de suivre les deux niveaux et d'en reconnaître les limites vers l'est, c'est-à-dire vers le fond du vallon.

6 Le second secteur qui a été sondé n'a livré aucun site. La présence d'un niveau argileux brun, à plus de $2 \mathrm{~m}$ de profondeur, riche en éclats de débitage et en outils de silex, indique une fréquentation du lieu mais pas une réelle occupation.

7 Elle informe également sur la puissance de la sédimentation dans les secteurs topographiquement les plus bas et, de ce fait, sur les difficultés de détecter les sites en simples repérages de surface.

8 Cette intervention a été du plus grand intérêt au vu des destructions consécutives aux travaux d'aménagements (autoroute A16 et zone industrielle) dans la région.

INDEX

Index chronologique : Antiquité romaine, bas Moyen Âge, Protohistoire Index géographique : Nord-Pas-de-Calais, Pas-de-Calais (62), Étaples

operation Prospection inventaire (PI) 